\title{
Ichthyosis vulgaris and pycnodysostosis: An unusual occurrence
}

\author{
Vinayak Y. Kshirsagar ${ }^{1}$, Minhajuddin Ahmed ${ }^{1}$, Suhel Nagarsenkar ${ }^{1}, K_{\text {Kulmani Sahoo }}^{2}$, \\ Kuldeep B. Shah ${ }^{3}$
}

${ }^{1}$ Department of Pediatrics, Krishna Institute of Medical Sciences University Krishna Hospital, Karad, Maharashtra, India ${ }^{2}$ Department of Radio diagnosis, Krishna Institute of Medical Sciences University Krishna Hospital, Karad, Maharashtra, India ${ }^{3}$ Krishna Institute of Medical Sciences University, Krishna Hospital, Karad Maharashtra, India

Corresponding author: Vinayak Y Kshirsagar Department of Pediatrics Krishna Institute of Medical Sciences University

Karad, Maharashtra India 415110

drkshirsagarvy@yahoo.com

Tel.: + 912164241555

Fax.: + 912164242170

Received: 5 February, 2012

Accepted: 22 August, 2012

Copyright (C) 2012 by

Academy of Sciences and Arts

of Bosnia and Herzegovina.

E-mail for permission to publish:

amabih@anubih.ba

\section{Introduction}

Pycnodysostosis is an autosomal-recessive disorder of osteoclasts due to mutation in the gene that codes enzyme Cathepsin $\mathrm{K}$ causing osteosclerosis $(1,2)$. The first case was described in 1923 by Montanari, but toderma.

\begin{abstract}
Pycnodysostosis is a rare autosomal recessive disorder whose gene responsible for this phenotype (CTSK), mapped to human chromosome 1q21, code for the enzyme cathepsin K, a lysosomal cysteine protease; with an estimated incidence of 1.7 per 1 million births. This clinical entity includes micromelic dwarfism, increased radiological bone density, dysplasia of the skull, acro-osteolysis, straightening of the mandibular angle and in some cases, dysplasia of the acromial end of the clavicle. Oral and maxillo-facial manifestations of this disease are very clear. Herein we reported a case of pycnodysostosis, showing short stature with widening of the sutures, unfused anterior and posterior fontanelles, crowding of teeth with dental caries and typical radiological features associated with ichthyosis vulgaris and palmoplantar keratoderma.
\end{abstract}

Key words: Pycnodysostosis, Ichthyosis vulgaris, Palmoplantar kera-

Maroteaux and Lamy defined the characteristic features in 1962. It has also been named Toulouse-Lautrec syndrome, after the French painter Henri de Toulouse-Lautrec, who suffered from the disease $(3,4)$. General features include short stature $(<150$ $\mathrm{cm}$ ), generalized diffuse osteosclerosis with tendency for fracture, hypoplastic clavicles and acro-osteolysis with sclerosis of terminal phalanges - a feature that is considered essentially pathognomic. Cranial and maxillo-facial features include fronto-parietal bossing, thick calvaria, open fontanelle and sutures, hypoplastic paranasal sinuses, wormian bones in the lamboidal region, relative proptosis, beaked nose and an obtuse 
mandibular gonial angle, often with relative prognathism (2).

Ichthyosis is the most frequent inherited disorder of keratinization. Filaggrin, a filament aggregating protein, that plays a role in the formation of the stratum corneum, has been shown to be altered in ichthyosis vulgaris. Mutations in the gene encoding this protein (FLG) have been found in patients presenting this skin abnormality (5). Different patterns of inheritance are described in ichthyosis, such as autosomal dominant, autosomal recessive and $\mathrm{X}$-linked. Mutations in FLG gene have been associated both with autosomal recessive and dominant modes of inheritance (5).

We report on a patient presenting typical features of pycnodysostosis and ichthyosis vulgaris. This association has never been described before.

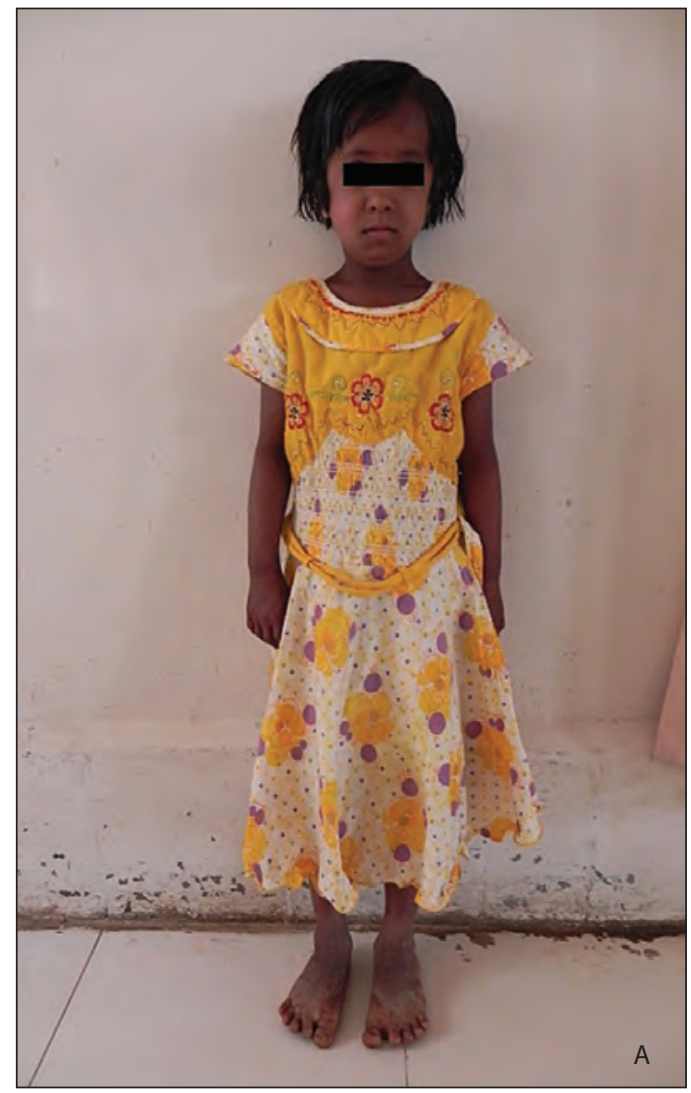

\section{Case report}

An 8-year-old female child, born by second degree consanguineous marriage presented to us with short stature, dysmorphic facies and ichthyosis since birth (Figure 1).

She evolved with delayed milestones. Her other siblings and parents are normal. On admission child's weight was $14.2 \mathrm{~kg}\left(<3^{\text {rd }}\right.$ percentile), height $105 \mathrm{~cm}\left(<3^{\text {rd }}\right.$ percentile $)$, upper segment $58 \mathrm{~cm}$, lower segment $47 \mathrm{~cm}$ and head circumference $50 \mathrm{~cm}$ (normal). The child has a history of recurrent upper airway tract infections and episodes of upper airway obstructions during sleep. She had mid facial hypoplasia with proptotic eyes, fronto-parietal bossing with separated sagittal, coronal and lamboid sutures with widely open anterior and posterior fontanelles. Examination of the mouth revealed

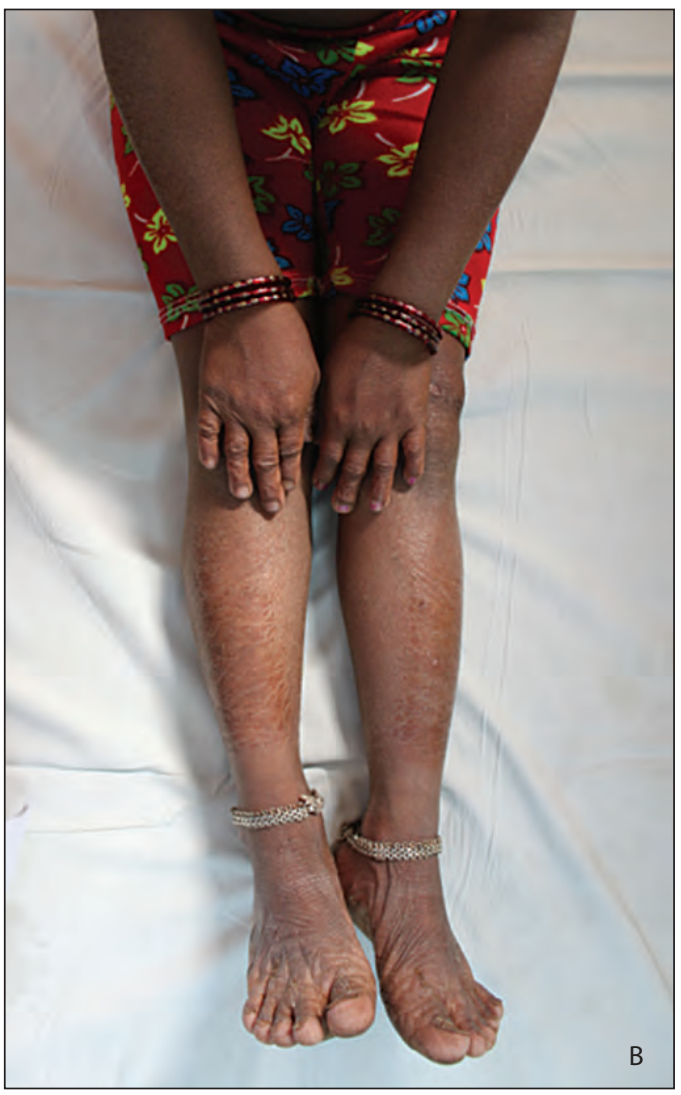

Figure 1 Clinical features of our patient: a) Dysmorphic facial features. b) Ichthyosis. 
a narrow high arched, grooved palate with crowding of the lower anterior teeth. Her digits were short, spoon shaped, stubby with no joint laxity, widening of the joints and dystrophic nails. Cutaneous examination revealed ichthyosis with palmoplantar keratoderma. Laboratory investigations including complete blood count, serum calcium, serum inorganic phosphate and alkaline phos-

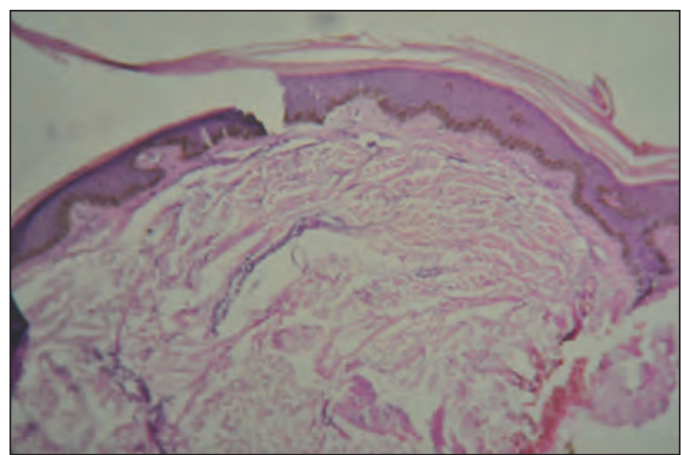

Figure 2 Superficial perivascular lymphocytic infiltrate with slight epidermal hyperplasia, granular layer in thinned with stratum corneum showing mild ortho hyperkeratosis.

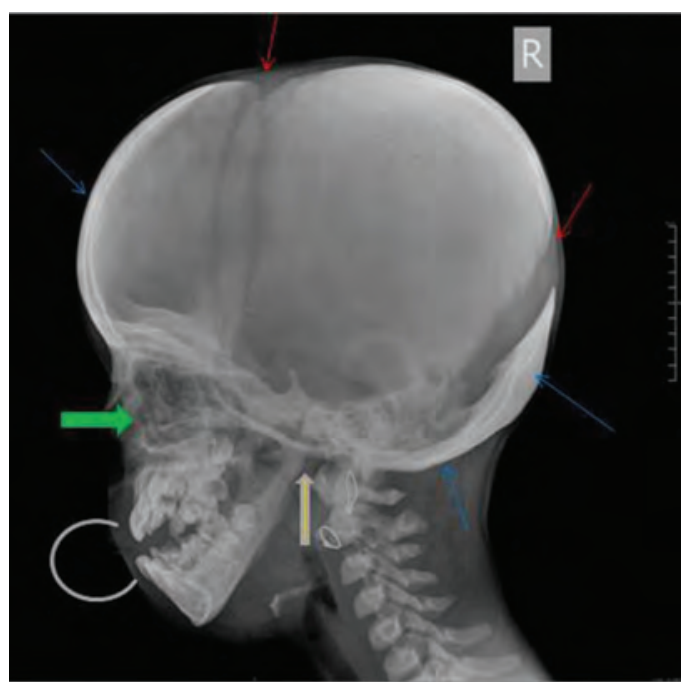

Figure 3 Failure of sutural fusion (red arrow); dense sclerosis of the frontal and occipital bone and base of the skull (blue arrow); obtuse angle of the mandible (thick yellow arrow); hypoplastic maxilla (thick green arrow); defective teeth (grey ring). phatase were within normal limits. The skin biopsy showed histopathological findings compatible with the diagnosis of ichthyosis vulgaris (Figure 2).

The radiographical findings disclosed generalized increase in bone density. Lateral view $\mathrm{X}$ ray of the skull (Figure 3) showed open anterior fontanelle with non pneumatized frontal and maxillary sinus and large calvarium while AP view of the skull (Figure 4), failure of sutural fusion with dense sclerosis, obtuse angle of mandible and hypoplastic maxilla. X ray of bilateral hands (Figure 5) showed loss of ungula tufts, tapering of distal phalanges with hypoplastic right thumb and destructive changes of distal phalanges.

Screening for ear defects (otosclerosis), fundus examination and intelligence quotient were normal. She was diagnosed as pycnodysostosis with ichthyosis vulgaris and palmoplantar keratoderma, which has not been reported previously. Genetical confirmation is not available, although the clinical data are strongly suggestive.

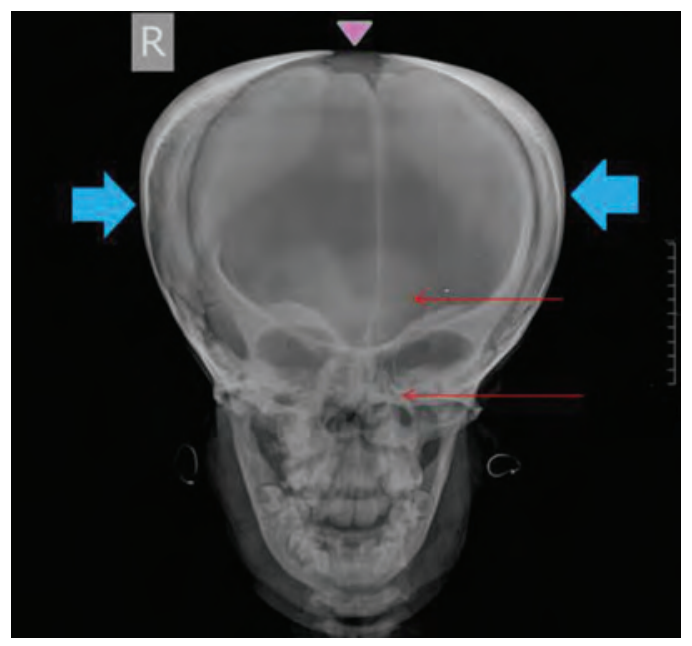

Figure 4 Open anterior fontanelle (pink triangle); non -pneumatized: frontal and maxillary sinus (red arrows); large calvarium (blue thick arrows). 


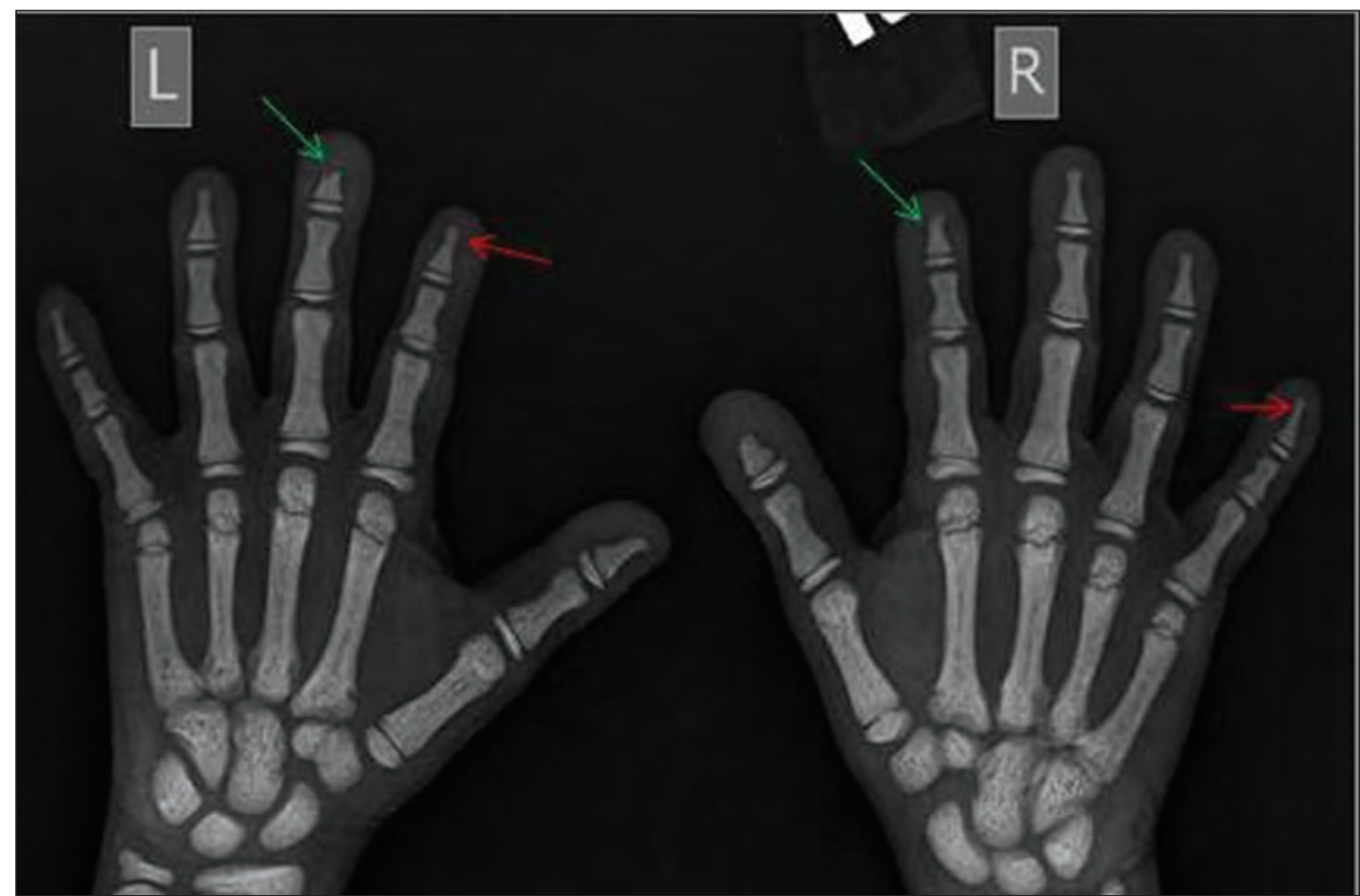

Figure 5 Loss of ungual tuft; tapering of distal phalanges (red arrows); destructive changes in the distal phalanges (green arrow).

\section{Discussion}

Pycnodysostosis is a disorder of lysosomal cysteine protease enzyme cathepsin $\mathrm{K}$, which maps to chromosome 1q21. Cathepsin $\mathrm{K}$ is highly expressed in osteoclasts and responsible for bone remodelling by degrading collagen type 1 that constitutes $95 \%$ of organic bone. Nonsense, missense, and stop codon mutations in the gene have been identified, which results in reduced expression of the enzyme. The bones become abnormally dense and brittle as a result of insufficient reabsorption process $(6,7,8)$. Pycnodysostosis is included in the group of disease that is caused by low bone remodeling (9).

Interestingly, this patient with typical features of pycnodysostoisis also presents ichthyosis vulgaris. This skin abnormality is considered a frequent single-gene disorder in humans (10) and, therefore, the co-occurrence of ichthyosis and pycnodysostosis in this case is a real possibility. Some genetic disorders have been associated with ichthyosis vulgaris, such as Refsum disease and multiple sulfatase deficiency, but not pycnodysostosis (11). On the other hand, the gene responsible for the autosomal dominant form of ichthyosis vulgaris was assigned to the same chromosomal region (1q21) of the one responsible for pycnodysostosis. Loss-of-function mutations in the filaggrin $(F L G)$ gene have been described in patients presenting ichthyosis. Although the moderate and severe cases showed homozygous or compound heterozygous mutations in this gene, milder conditions were associated with a mutation in a single allele (5). Based on the facts that the genes for pycnodysostosis (CTSK) and for ichthyosis vulgaris (FLG) are in close proximity and that both disorders are due to loss-of-function mutations, it is tempting to speculate that a microdeletion in the region 1q21 could cause the loss 
of both genes in one allele. The association of this microdeletion with a further mutation in the other allele of the CTSK gene could be responsible for the association of pycnodysostosis and ichthyosis vulgaris in this patient. Unfortunately, this possibility could not be proved due to unavailability of the molecular tests in our Country.

Various bone diseases should be considered in the differential diagnosis of pycnodysostosis, particularly the ones that evolve with increased bone density and acroosteolysis as well as cleidocranial dysostosis, a disorder which also shows persistence of open fontanelles and cranial sutures at an advanced age. This disorder has an autosomal dominant mode of inheritance and is characterized by absent or hypoplastic clavicles, permitting abnormal facility apposing the shoulders and supernumery teeth with impacted permanent teeth (11). There is no specific treatment for pycnodysostosis for this disorder. Once bone fractures are the primary threat to those individuals affected by pycnodysostosis, a supportive care is important to prevent or minimize fractures that could occur.

\section{Conclusion}

This case is reported for its rarity and unusual cutaneous association of ichthyosis vulgaris and palmoplantar keratoderma, as no case has been reported this far. Although we cannot rule out for certainty that icthyosis and pycnodysostosis occured by chance in this patient, there is a possibility that a microdeletion in one allele comprising the genes of these two disorders is responsible for this unusual association.

Authors' contributions: Conception and design: VYK, MA, SN; Acquisition, analysis and interpretation of data: MA,VYK, KS; Drafting the article: MA,VYK, KS; Revising it critically for important intellectual content: VYK, MA.
Conflict of interest: The authors declare that they have no conflict of interest. This article was not sponsored by any external organization.

\section{References}

1. Mujawar Q, Naganoor R, Patil H, Thobbi AN, Ukkali S, Malagi N. Pycnodysostosis with unusual findings: a case report. Cases J. 2009; 2:6544.

2. Fleming KW, Barest G, Sakai O. Dental and facial bone abnormalities in pyknodysostosis: CT findings. AJNR Am J Neuroradiol. 2007;28(1):132-4.

3. Clark AR. Two cases of pycnodysostosis (the malady of Toulouse-Lautrec). Postgrad Med J. 1969;45(528):684-7.

4. Maroteaux P, Lamy M. Pyknodysostosis. Presse Med. 1962;70:999-1002.

5. Smith FJ, Irvine AD, Terron-Kwiatkowski A, Sandilands A, Campbell LE, Zhao Y, et al. Lossof-function mutations in the gene encoding filaggrin cause ichthyosis vulgaris. Nat Genet. 2006;38(3):337-42.

6. Elmore SM. Pycnodysostosis: a review. J Bone Joint Surg Am. 1967;49:153-62.

7. Motyckova G, Fisher DE. Pycnodysostosis: role and regulation of cathepsin $\mathrm{K}$ in osteoclast function and human disease. Curr Mol Med. 2002;2(5):407-21.

8. Gelb BD, Shi GP, Chapman HA, Desnick RJ. Pycnodysostosis, a lysosomal disease caused by cathepsin K deficiency. Science. 1996;273(5279):1236-8.

9. Chavassieux P, Seeman E, Delmas PD. Insights into material and structural basis of bone fragility from diseases associated with fractures: how determinants of the biomechanical properties of bone are compromised by disease. Endocr Rev. 2007;28(2):151-64

10. Wells RS, Kerr CB. Clinical features of autosomal dominant and sex-linked ichthyosis in an English population. Br Med J. 1966;1(5493):947-50.

11. Oji V, Traupe H. Ichthyoses: differential diagnosis and molecular genetics. Eur J Dermatol. 2006;16(4):349-59. 